\title{
Research on Power Consumption Management of Rural Irrigation Based on Intelligent Ammeter
}

\author{
Meng Zhang ${ }^{1, a}$, Man Cheng ${ }^{1, b}$, Lei Sun ${ }^{1, c}$, Limin Shao ${ }^{1, d^{\star}}$ and Xuesong Suo ${ }^{1, e}$ \\ ${ }^{1}$ College of Mechanical and Electrical Engineering, Agricultural University of Hebei, Baoding 071001, \\ China \\ azhangmeng8426@163.com, ${ }^{b} 58846407 @ q q . c o m,{ }^{c}$ slsIsI0811@126.com, ${ }^{d}$ shaolm@126.com, ${ }^{\mathrm{e}} 10$ \\ 5881200@qq.com
}

Corresponding Author: Limin Shao

Keywords: Rural irrigation, power consumption management, intelligent ammeter.

\begin{abstract}
This project is based on the installation of intelligent electric ammeter, researches on power consumption management of rural irrigation. It can solve some problems in the rural irrigation power consumption management, can make a breakthrough, research results will provide theoretical and technical support to the management, and has an important practical significance. Study on this project will improve the level of power management for irrigation in rural areas, is conducive to the improvement of rural power supply quality, and bring practical benefits for farmers, is conducive to the construction in rural power network reform and rural smart grid.
\end{abstract}

\section{Introduction}

Promoting rural power grid is an important content of building the smart grid. Strong and reliable, cost-effective, clean and environmentally friendly, transparent and open are the basic meanings of the rural network intelligence. It should improve the power management, operation and transmission efficiency, improve the technical level of equipment, and provide high quality power supply, low power consumption, promote efficient use of energy in the rural power grid [1]. However, there are still some problems of the rural power grid management, especially in irrigation power consumption management [2], which restricts the development level of rural power consumption management. Research on this project will help to improve the irrigation of rural power consumption management level, will help improve the quality of rural power supply, and bring benefits to the farmers, help rural grid reform and construction of rural smart grid.

\section{Status and problems of rural irrigation power consumption management}

\subsection{Status of rural irrigation power consumption management.}

Rural irrigation power management has a lot of blind spots, through the development of rural power grids and smart grid, rural power management level has improved in some degree, but due to the limitations of rural power system, the management status of rural irrigation electricity still falls behind[3-4]. Most rural areas still have not installed intelligent ammeters, the area installation of smart ammeters just using for getting electricity charge, does not apply in the field of power consumption management[5-6], resulting in the rural irrigation power consumption management remains the disadvantage of the following aspects:

(1) Since the electricity facility property diversification, "human feelings electricity, relations electricity" and other issues, the price of electricity is not standardized management

(2) Poor rural irrigation electrical equipment, the presence of connecting wires without permission, there are many security risks, can easily result in personal electric shock.

(3) Irrigation electricity shows remarkable seasonality, power grid capacity can not meet the fast-growing load demand, irrigation peak power quality decline, bring inconvenience to power users. 


\subsection{Problems of rural irrigation power consumption management.}

Key issues of the rural irrigation power management are that professionals of the power enterprises should check the existing unsafe electrical behavior in rural areas, in time to stop; electricity stealing is serious, to increase the inspection efforts of electricity use in rural areas, set up a special supervision and management departments [7]. Remarkable seasonality of irrigation power, transformers often at full load (sometimes overload) running, irrigation peak power quality decline. After the autumn harvest, most of the transformers lie idle, causing unnecessary waste of energy [8]. In recent years, increase investment in rural farmland irrigation and drainage projects focused launched. On the construction of rural power grid, historical debts are existence, new projects approval difficult, insufficient funds, long construction period, these problems caused power grid capacity can not meet the fast-growing load demand.

\section{Rural irrigation power consumption management scheme}

To solve the above problems, a rural irrigation power consumption management method is based on the intelligent pumped wells ammeter. An intelligent pumped well ammeter has multi-cards for several users, electricity unit price is set, infrared measurement and other functions [9]. Based on this kind of ammeter, can reasonably basis of the card for each user's charge; and convenient for managing; new irrigation methods, flexibility in water supply link charged management fees; easy segment maintenance, to ensure user safety, and prevent the presence of connecting wires without permission; count on electricity for irrigation combined with rainfall, short-term and long-term prediction to ensure that the supply of power and power quality.

At present, the study of power consumption management for rural irrigation is still not comprehensive. The power card program, an establishment of "a well, a line" and "an ammeter, multi-cards" is the agricultural irrigation construction and renovation mode. Using of pre-paid card mode, the original charge by the pumped well instead by users. The operator simply sets electricity prices (which can cause additional water and equipment cost) for each user in the management software, it can realize the personal charges. Intelligent ammeters not only has unit conversion, auto-zero function, but also have powerful automatic measurement and data processing capabilities, thus promoting the use of intelligent ammeters has important significance in improving the efficiency of the power management. Application of low voltage automatic carrier wave power consumption measurement system can solve the difficult in charging agricultural irrigation electricity management fees, low power and irrigation efficiency, electricity stealing and other issues. The design of power consumption management system and the application of intelligent ammeter can provide reference for improving the management level and efficiency of electricity.

\section{Management program function design}

According to the present situation of the rural irrigation power consumption management, the main design plan is as follows:

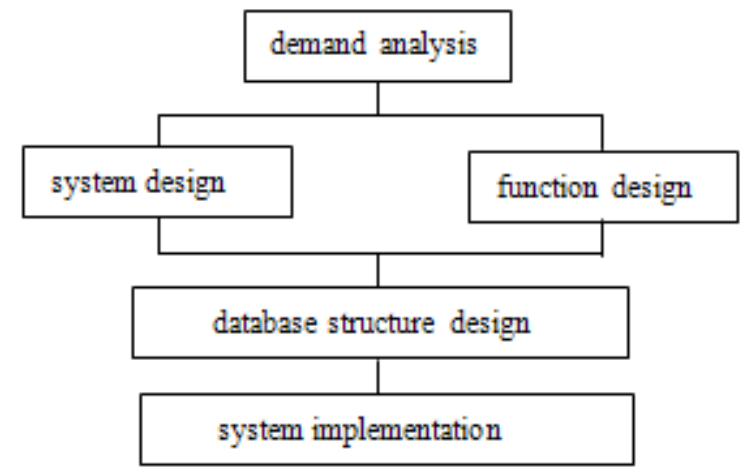

Fig. 1 Design of management system

(1) Demand analysis of rural irrigation power consumption management 
Research on rural areas in Baoding for the status of rural irrigation power and smart grid development analyzes the demand of rural power consumption management. Based on intelligent pumped well ammeters, rural power consumption management should implement electricity charge management, power quality monitoring, electricity short-term and long-term prediction [10].

(2) Rural irrigation power consumption management design based on pumped wells intelligent ammeter

Using intelligent ammeters for rural irrigation power consumption management. Through intelligent ammeters, communication equipments, acquisition equipments, collect data tables include: concentrator information table, acquisition information table, smart ammeters information table, electricity price information table and configuration tables, as shown in Table 1 [11]. Operational data include: mainly used for real-time data recording each ammeter. Statistics include: daily consumption statistics, user power outage information tables, power quality statistics tables. Daily consumption statistics is mainly used for electricity users to count electricity consumption; user power outage information is user information for power outage statist; power quality statistics is mainly used for user power quality management. Real-time data monitoring function can monitor specified user in the control center to monitor the smart ammeters, to prevent electricity stealing, conducive to on-site service. Historical data can be stored statistical functions, statistical measurement data smart ammeters to save all kinds of ammeter reading data recording and monitoring data, to generate an image, and print. The electricity historical data can be used as the basis of the load data, then automatically copy the data, save to the database. Using historical data combined with weather forecasts can be short-term and long-term forecasts of electricity for irrigation. Fameview application software platform based on Microsoft SQL Server 2005 database technology achieve the function of rural irrigation power consumption management system.

Table 1 Data collection table

\begin{tabular}{lll}
\hline Equipment & \multicolumn{1}{c}{ Function } & \multicolumn{1}{c}{ Characteristic } \\
\hline \multirow{2}{*}{ Concentrator } & 1) Power quality monitoring and management & 1) multi-function \\
& 2) Energy metering & 2) low power \\
Intelligent & 2) divided-period price & 3) interaction \\
ammeter & 3) remote control & 1) low power \\
& 4) intelligent reminder & 2) high precision
\end{tabular}

(3) Design optimization

The power management system based intelligent wells applies surrounding Baoding rural areas, and the design improves in engineering.

1) Function design

According to the above design ideas for rural irrigation power consumption management, implemented features include: electricity charge management, real-time data monitoring, historical data inquiry, power quality analysis, supply reliability analysis, electricity forecasting and equipment maintenance management.

2) System database structure design

According to the demand analysis and database design principles, clear data by name, the amount of data size, scope and relationships involved each database table structure will be divided into ammeter data table, operating data table and statistics table.

3) Functions to achieve

For the demand of rural irrigation power consumption management, combined with software platform architecture, database design, software and hardware constitution and other related technologies. In the rural irrigation management system based on intelligent pumped well ammeter, the application of Fameview platform, used with FusionCharts graphics production technology based 
on Flash, the reporting software, Microsoft SQL Server 2005 database technology can achieve the functions of the system.

\section{Conclusion}

At present, there are still some problems in rural irrigation power consumption management. Therefore, the related departments should focus on the existent problems; take effective measures to solve them, continuously increasing the power efficiency of agricultural irrigation.

\section{Acknowledgements}

This study was supported by Baoding City Science \& Technology Bureau Research Project (15ZG012, 15ZG011), Polytechnic Foundation of Agricultural University of Hebei (LG20140203) and Young Academic Leaders of Hebei Agricultural University.

\section{References}

[1]. Jianlong Li. Research on project management of rural smart grid construction based on life cycle theory. (D, North China Electric Power University, China 2012).

[2]. Feng Feng, Baoxia Li. Analysis of focus problems of rural irrigation power consumption management. Enterprise Reform and Management. (2014) No.8, p. 165.

[3]. Huajun Li. Research on low-voltage rural power network treatment and rural power network research upgrading. Science \& technology information. (2013) No.16, p. 141.

[4]. Ying Qi. The Research of network upgrading project. (D, Shandong University, China 2013).

[5]. Zhi Wang. Smart Meter Application Research in the Countryside. Science and Technology \& Innovation. (2014) No.22, p. 69-70.

[6]. Feng Lu, Zhenyu Wang, Jun Shen, et al. Rural-oriented Intelligent Distribution Area and Application. Journal of Shanghai University of Electric Power. Vol. 30 (2014) No.z1, p. 4-7.

[7]. Hongwen Yu. Problems and countermeasures of rural irrigation electricity. Price Supervision and Anti-Monopoly in China. (2012) No.6, p. 23.

[8]. Shaohua Pan. Research on the Comprehensive Treatment of Rural Low Voltage Phenomenon. China Electric Power (Technology Edition). (2011) No.11, p.63-65.

[9]. Xinchun Jie, Wenshen Chen. Design and Application of Agricultural Irrigation Hydropower Management System Based on Wireless Transmission Network. Water Resources and Power. (2011) No.12, p. 143-146.

[10]. Yanyu Zhang, Peng Zeng, Chuanzhi Zang. Review of home energy management system in smart grid. Power System Protection and Control. (2014) No.18, p. 144-154.

[11]. Qiyi Li. Design and implementation of remote meter reading system in the smart grid. China Equipment. (2014) No.s2, p. 178+181. 